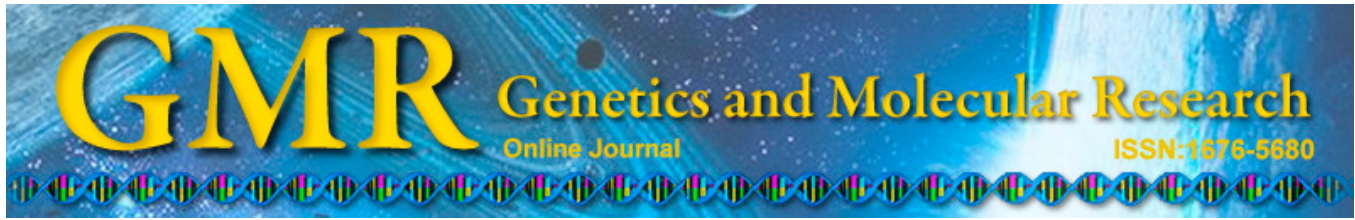

\title{
Development and characterization of polymorphic microsatellite markers for Castanopsis hystrix (Fagaceae)
}

\author{
Y. Jiang ${ }^{1,2}$, Z.H. Li ${ }^{1}$ J.Y. Zhu ${ }^{2,3}$ and H.L. Liu ${ }^{1,2,3}$ \\ ${ }^{1}$ Central South University of Forestry and Technology, Changsha, China \\ ${ }^{2}$ Guangxi Academy of Forestry, Nanning, China \\ ${ }^{3}$ Guangxi Key Laboratory of Superior Timber Trees Resource Cultivation, \\ Nanning, China
}

Corresponding author: Y. Jiang

E-mail: jiangyi6808@gmail.com

Genet. Mol. Res. 14 (1): 2436-2439 (2015)

Received February 18, 2014

Accepted September 17, 2014

Published March 30, 2015

DOI http://dx.doi.org/10.4238/2015.March.30.1

\begin{abstract}
Castanopsis hystrix is one of the most important and dominant species in evergreen broad-leaved forests in subtropical China. However, the population of this species undergone severe decline because of deforestation over the past 2 decades. For both conservation and forestry management, it is essential to develop molecular markers for $C$. hystrix. We identified 11 microsatellite loci in 2 wild populations. The number of alleles ranged from 3-11, with an average of 6.45 alleles per locus. The observed and expected heterozygosities ranged from $0.640-0.960$ and from $0.676-0.910$, respectively.
\end{abstract}

Key words: Castanopsis hystrix; Genetic structure; Microsatellite markers 


\section{INTRODUCTION}

Castanopsis hystrix is an evergreen tree species and a fagaceous species that originated in south China and Indochina ( $\mathrm{Li}, 1996)$. The extensive use of $C$. hystrix wood, such as for construction and boat building, has largely decreased the population and contributed to genetic erosion. To support the conservation of this species, the Chinese government established a provincial nature reserve in Luhe, Guangdong Province in 2001. Currently, most of the efforts have focused on the breeding and cultivation of this species (Zhu et al., 2005). The study of genetic diversity and population genetic structure of $C$. hystrix is insufficient and limited, making the development of genetic markers of $C$. hystrix important and necessary. The goal of this study was to develop molecular microsatellite markers that can be used to understand the genetic diversity and population biology of C. hystrix.

\section{MATERIAL AND METHODS}

An improved technique for isolating codominant compound microsatellite markers (Lian et al., 2006) was used to develop simple sequence repeat (SSR) markers for C. hystrix. First, an adaptor-ligated DNA library was constructed according to the protocol of Lian et al. (2001). Briefly, approximately $250 \mathrm{ng}$ total genomic DNA extracted from silica-gel-dried leaf material was digested by the blunt-end restriction enzyme EcoRV (Takara, Shiga, Japan). The restricted fragments were ligated to an unequal-length adaptor using the DNA Ligation Kit Version 2.0 (Takara). Next, fragments flanked by a microsatellite at one end were amplified from the EcoRV DNA library using a compound SSR primer $(\mathrm{AC})_{6}(\mathrm{AG})_{5}$ and an adaptor primer AP2 (5'-CTATAGGGCACGCGTGGT-3'). Fragments amplified from the EcoRV DNA library were purified and ligated into a PMD18-T vector (Takara) and transformed into JM109 competent cells (Takara). Transformants were cultured on selective agar media containing ampicillin, 5-bromo-4-chloro-3-indolyl- $\beta$-D-galactopyranoside, and isopropyl $\beta$-D-1thiogalactopyranoside, for blue/white colony selection. After polymerase chain reaction (PCR) to test for insert size of the white colonies, 212 positive colonies with the fragment of expected size were sequenced using an ABI 3730 DNA sequencer (Applied Biosystems, Foster City, CA, USA). Eighty-nine sequences were found to contain $(\mathrm{AC})_{6}(\mathrm{AG})_{\mathrm{n}}$ compound SSR motifs. However, 43-89 sequences were discarded either because the repeat was too close to one end of the insert to design a suitable primer. Therefore, only 46 sequences containing $(A C)_{6}(A G)_{n}$ compound SSR sequences at one end were suitable for designing primers, and a specific primer (IP1) was designed using PRIMER version 5.0 (Clarke and Gorley, 2001) from the sequences flanking the compound SSR. The primer pairs of IP1 and the compound SSR primer were used as a compound SSR marker (Table 1). The PCR was performed in $10-\mu \mathrm{L}$ reaction volumes containing 30-50 ng/ $\mu \mathrm{L}$ template DNA, $0.25 \mathrm{U}$ Taq DNA polymerase (Takara), 1X PCR buffer, $1 \mu \mathrm{L} 2.5 \mathrm{mM} \mathrm{MgCl}, 1 \mu \mathrm{L} 2.5 \mathrm{mM}$ dNTPs, $0.1 \mu \mathrm{L}$ bovine serum albumin (Takara), and $1 \mu \mathrm{L}$ $10 \mu \mathrm{M}$ of each primer. The thermal profile used was for initial denaturation for $5 \mathrm{~min}$ at $95^{\circ} \mathrm{C}$, followed by 30 cycles of $30 \mathrm{~s}$ at $95^{\circ} \mathrm{C}, 45 \mathrm{~s}$ of annealing at the optimized annealing temperature (Table 1), 1 min $30 \mathrm{~s}$ of elongation at $72^{\circ} \mathrm{C}$, ending with a 10 -min extension at $72^{\circ} \mathrm{C}$. A total of 19 of the 43 primer pairs tested successfully amplified the target fragments. These PCR products were further resolved on $6 \%$ polyacrylamide denaturing gel using a 50-bp ladder (Takara) as the reference and visualized by silver staining. To obtain accurate data, the forward primer of each pair was labeled with a fluorescent dye (6-FAM or HEX) (Table 1). PCR amplifica- 
tion was conducted as described. Fragment analysis was performed on a MegaBACE 1000 autosequencer (GE Healthcare Biosciences, Little Chalfont, UK), and the data were scored and compiled using GENETIC PRO-FILER version 2.2 (GE Healthcare Biosciences).

\section{RESULTS}

A total of 19 microsatellite loci were identified, of which 11 were polymorphic (Table 1). Across 25 individuals from 2 populations, the number of alleles per locus ranged from 3-11 with an average of 6.45. The observed and expected heterozygosities $\left(H_{\mathrm{O}}\right.$ and $\left.H_{\mathrm{E}}\right)$ ranged from $0.640-0.960$ and from $0.676-0.910$, respectively. The polymorphic information content ranged from $0.588-0.882$, with an average of 0.766 , calculated with CERVUS version 3.0.3 (Kalinowski et al., 2007). No loci displayed significant deviation from Hardy-Weinberg equilibrium ( $\mathrm{P}<0.05$ with Bonferroni's correction), tested using Genepop (Rousset, 2008). No significant linkage disequilibrium was detected between any pair of loci.

Table 1. Information and characteristics of 11 compound microsatellite loci in Castanopsis hystrix $(\mathrm{N}=25)$.

\begin{tabular}{|c|c|c|c|c|c|c|c|c|}
\hline $\begin{array}{l}\text { Locus GenBank. } \\
\text { accession No. }\end{array}$ & Repeat & Primers & $\begin{array}{l}\text { Size range } \\
\text { (bp) }\end{array}$ & $\mathrm{Ta}\left({ }^{\circ} \mathrm{C}\right)$ & $N_{\mathrm{A}}$ & $H_{\mathrm{O}}$ & $H_{\mathrm{E}}$ & PIC \\
\hline \multirow[t]{2}{*}{ Ch1 KF725650 } & $(\mathrm{AC})_{6}(\mathrm{AG})_{9}$ & F: ACACACACACACAGAGAGAGAG & & & & & & \\
\hline & & R: CCGTCAAGTAGGGATAGCAGA & $143-187$ & 52 & 5 & 0.640 & 0.798 & 0.748 \\
\hline \multirow[t]{2}{*}{ Ch2 KF725651 } & $(\mathrm{AC})_{6}(\mathrm{AG})_{14}$ & F: ACACACACACACAGAGAGAGAG & & & & & & \\
\hline & & R: GAAAATGAAGCCATAGTC & $144-178$ & 54 & 5 & 0.720 & 0.747 & 0.690 \\
\hline \multirow[t]{2}{*}{ Ch3 KF725652 } & $(\mathrm{AC})_{6}(\mathrm{AG})_{5}$ & F: ACACACACACACAGAGAGAGAG & & & & & & \\
\hline & & R: ACAACACCAATCTCCTTAGC & $138-166$ & 51 & 4 & 0.760 & 0.729 & 0.660 \\
\hline \multirow[t]{2}{*}{ Ch4 KF725653 } & $(\mathrm{AC})_{6}(\mathrm{AG})_{6}$ & F: ACACACACACACAGAGAGAGAG & & & & & & \\
\hline & & R: AGATTGGTGGTGGGAGGGGT & $213-281$ & 55 & 6 & 0.960 & 0.829 & 0.785 \\
\hline \multirow[t]{2}{*}{ Ch5 KF725654 } & $(\mathrm{AC})_{6}(\mathrm{AG})_{8}$ & F: ACACACACACACAGAGAGAGAG & & & & & & \\
\hline & & R: CTGAAATCGTAGGCAGTGAC & $166-198$ & 56 & 6 & 0.840 & 0.830 & 0.787 \\
\hline \multirow[t]{2}{*}{ Ch6 KF725655 } & $(\mathrm{AC})_{6}(\mathrm{AG})_{6}$ & F: ACACACACACACAGAGAGAGAG & & & & & & \\
\hline & & R: TGGGCATCCAAATCACTAA & $158-188$ & 55 & 9 & 0.800 & 0.893 & 0.862 \\
\hline \multirow[t]{2}{*}{ Ch7 KF725656 } & $(\mathrm{AC})_{6}(\mathrm{AG})_{19}$ & F: ACACACACACACAGAGAGAGAG & & & & & & \\
\hline & & R: CCATGAGGTTGATTTACTTTTT & $178-212$ & 52 & 5 & 0.880 & 0.808 & 0.759 \\
\hline \multirow[t]{2}{*}{ Ch8 KF725657 } & $(\mathrm{AC})_{6}(\mathrm{AG})_{7}$ & F: ACACACACACACAGAGAGAGAG & & & & & & \\
\hline & & R: TGCTAACGTCAATGAAACC & $167-203$ & 52 & 3 & 0.800 & 0.676 & 0.588 \\
\hline \multirow[t]{2}{*}{ Ch9 KF725658 } & $(\mathrm{AC})_{6}(\mathrm{AG})_{5}$ & F: ACACACACACACAGAGAGAGAG & & & & & & \\
\hline & & R: TGAGAATGGCACCTTTGAT & $167-195$ & 54 & 7 & 0.880 & 0.865 & 0.829 \\
\hline \multirow[t]{2}{*}{ Ch10 KF725659 } & $(\mathrm{AC})_{6}(\mathrm{AG})_{5}$ & F: ACACACACACACAGAGAGAGAG & & & & & & \\
\hline & & R: TAATAAGACAACCGAAAATCAT & $343-381$ & 53 & 8 & 0.840 & 0.870 & 0.836 \\
\hline \multirow{2}{*}{ Ch11 KF725660 } & $(\mathrm{AC})_{6}(\mathrm{AG})_{18}$ & F: ACACACACACACAGAGAGAGAG & & & & & & \\
\hline & & R: CTTGAGACGACCAACGAAAC & $179-223$ & 55 & 11 & 0.960 & 0.910 & 0.882 \\
\hline
\end{tabular}

Ta $=$ optimized annealing temperature; $N_{\mathrm{A}}=$ total number of alleles per locus; $H_{\mathrm{O}}=$ observed heterozygosity; $H_{\mathrm{E}}=$ expected heterozygosity; PIC = polymorphism information content.

\section{DISCUSSION}

The microsatellites described in this paper will be a useful for studying the genetic variability and population structure of $C$. hystrix, and will promote its management and preservation. They are also expected to be helpful in future studies of genetic variation and population ecology in this species and other species in the Castanopsis genus.

\section{ACKNOWLEDGMENTS}

Research supported by the Project of Breeding and high yield cultivation mode re- 
search of Castanopsis hystrix (Funding \#10100012-3).

\section{REFERENCES}

Clarke KR and Gorley RN (2001). Primer V5: User Manual/Tutorial. Primer-E Ltd., Plymouth.

Kalinowski ST, Taper ML and Marshall TC (2007). Revising how the computer program CERVUS accommodates genotyping error increases success in paternity assignment. Mol. Ecol. 16: 1099-1106.

Li JQ (1996). The origin and distribution of the family Fagaceae. Acta. Phytotaxon. Sin. 34: 376-396.

Lian CL, Zhou ZH and Hogetsu T (2001). A simple method for developing microsatellite markers using amplified fragments of inter-simple sequence repeat (ISSR). J. Plant Res. 114: 381-385.

Lian CL, Wadud MA, Geng Q and Shimatani K (2006). An improved technique for isolating codominant compound microsatellite markers. J. Plant Res. 119: 415-417.

Rousset F (2008). genePop'007: A complete re-implementation of the GenePop software for Windows and Linux. Mol. Ecol. Resour. 8: 103-106.

Zhu JY, Jiang Y, Liang RL and Lu LH (2005). A preliminary report on tree planting test of provenances and families of Castanopsis hystrix in Guangxi. J. West China Forestr. Sci. 34: 5-9. 